\title{
Dynamic Response of the full-scale Straddle-type Monorail Vehicles with Single-axle Bogies
}

\author{
Junchao ZHOU*, Zixue DU**, Zhen YANG*** \\ *Institute of Urban Rail, Chongqing Jiao tong University, Chong Qing 400074, PR. China, E-mail: zhou1987g@163.com \\ School of Mechanical Engineering and Artificial Intelligence Key Laboratory of Sichuan Province, Sichuan University of \\ Science and Engineering, Zigong, Sichuan ,643000, PR. China \\ **Institute of Urban Rail, Chongqing Jiaotong University, Chong Qing 400074, PR. China, E-mail: aaadzx@163.com. \\ ***Institute of Urban Rail, Chongqing Jiao tong University, Chong Qing 400074, PR. China, E-mail: 21930315@qq.com \\ crossref http://dx.doi.org/10.5755/j01.mech.25.1.21931
}

\section{Introduction}

With the development of cities, the problem of heavy traffic is increasingly obvious in big cities. The straddle-type monorail system, as a unique urban transportation means, meets the mass transit requirements. The straddle-type monorail system has a large number of advantages such as small radius of turning circles and grade ability, light axle beams, low fabrication cost and low noises due to rubber tires so that it has been an urban rail transit research clique with middle and low traffic volume widely applied [1].The straddle-type monorail vehicles can be divided into two vehicle models, i.e., the "double-axle type model" and the "single-axle type model", represented by China Changchun Railway Vehicles, Hitachi and Bombardier, Scomi, respectively. The radius of Bombardier Monorail300 steering circles is 46m (which has been applied in St. Paulo. Brazil). Compared with Hitachi with the radius of turning circles of $100 \mathrm{~m}$, it is more flexible; besides, the grade ability is as high as $6 \%$, which adapts to mountain topography. The vehicle height with the singleaxle bogie is $4.05 \mathrm{~m}, 1.25 \mathrm{~m}$ lower than Hitachi. The system performance is greatly improved by the system returning rate employing increasing vehicle width.

Ride comfort is one of the most important dynamic performance characteristics of monorail vehicles and is affected by various factors, such as vibration, acoustic sound, smell, temperature, visual stimuli, humidity and seat design. In general, vibration is known to be a major factor that affects ride comfort. In terms of ride comfort, On the one hand, it mainly deals with the study of dynamics. Attention on the compatibility between stability and curving performance in tight curve radius of on the vehicle with single-axle truck and curving simulations using multibody dynamics software were made to examine the effect of the truck parameters such as secondary stiffness and characteristics of dampers [2]. The implemented model was used to simulate in time domain the dynamic behaviour of a vehicle running on irregular track and numerical results are validated by means of comparison with experimental data of on-line tests [3]. Relationships between several evaluation methods using a vibration model resulting from frequency analysis and statistical analysis of acceleration measurements of railway vehicles was present [4]. The effects of railway vehicle speeds on riding quality and comfort evaluated using both the Spelling and modified formulas are presented for the linear and nonlinear creep models of curved tracks [5]. Since ride comfort is deter- mined by road roughness and vehicle properties, the uncertainty of ride comfort results from the uncertainties of road roughness and vehicle property data. based on that, a statistical method employing the first order sensitivity information is used to evaluate the ride comfort uncertainty [6]. In the reference [7], the human body is considered as lumped masses, which represent the different body segments and are interconnected by springs and dampers and a human biodynamic model with dynamic seat characteristics is necessary in order to perform true comfort analysis. The reference [8] presented an approach to upgrade a bogie suspension (without a damaging) and thus to increase vibration isolation of a car body in the infra frequency range, which is most important for ride comfort. The longitudinal dynamic model of the passenger train for the attainment of better vehicle ride quality and comfort was analyzed [9]. on the other hand, estimating the dynamic responses of existing or proposed vehicles has a wide array of applications in the development of vehicle technologies, e.g. active suspensions, controller design, driver assistance systems, etc [10]. Besides, A method to optimize the alignment of horizontal curves to enhance train ride comfort and running stability when horizontal and vertical curves are superimposed in the case that railway construction/renovation was presented [11]. The vibration characteristics of the new single-axle bogie are discussed in the paper.

In the case of straddle-type monorail dynamics modelling, the literature [12-14] establishes a coupling dynamics model for the straddle-type monorails with double-axle bogies. To assess the dynamic behaviour of monorail-bridge system, an innovative model of train-guide way interaction has been developed based on multi-body dynamics and finite element simulation [12]. An analytical procedure of dynamic interaction analysis of the straddle monorail bridge-vehicle coupling system is proposed in this paper based on the finite element method and energy method [13]. A mathematical model of a straddle type monorail vehicle has been developed in order to study its stability and the effect of tire modelling techniques on its dynamic response [15]. Above the reference, lateral and roll dynamics of the monorail vehicles is considered but the longitudinal dynamics is neglected.

From the dynamic of the straddle-type single-rail vehicles with single-axle bogies, the "tire-rail coupling" dynamic model is established employing multi-body dynamic in this article, to conduct vibration response on velocity and tire stiffness. The tire-track beam contact model 
is established in this article. The dynamic model for straddle-type vehicles with single-axle bogies of 34 degree of freedom is established, including mainly plunging motions, nodding motions, yawing motions, transverse motions and rolling motions.

The rest parts of the article are arranged as follows: 1 . The structural characteristics of single-axle bogies are introduced; 2 . The motion equations of straddle-type vehicles with single-axle bogies is established, involving in plunging motions, nodding motions, yawing motions, transverse motions and rolling motions; 3. Results and analysis; 4. Conclusions

\section{Structural characteristics of single-axle bogies}

The bogie is the key of monorail vehicles, and it is illustrated in Fig 1. The single-axle bogie is composed by the framework, the running tire, the air suspension, the vertical and lateral damper. The simplex pull rod balancing bar is adopted in this article, which is equipped on the front end beam of the bogie. In addition, considering that the running tire is set in the middle of the bogie, the central traction pin with double-axle is not applicable, and the simplex poll rod traction device is adopted to deliver the traction power between the vehicle body and the bogie. Considering that the running tire set is placed in the middle, the air suspension, the vertical and lateral oil damper are arranged on both sides of the steady tire which are placed on both sides of the middle part of the bogie [1].

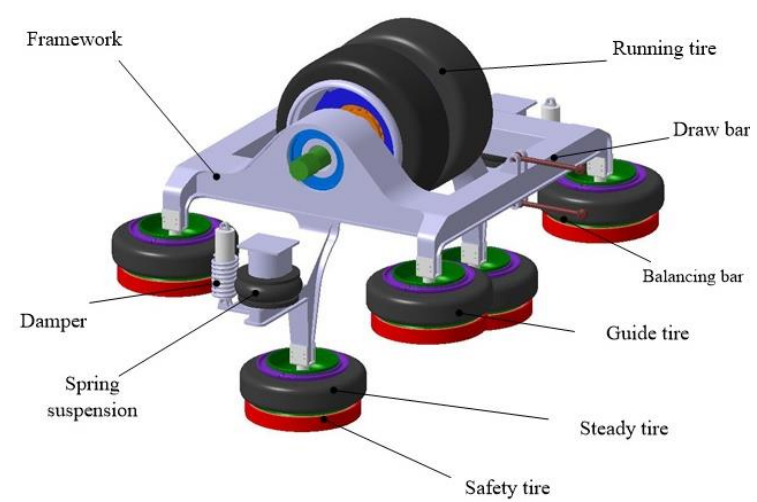

Fig. 1 Bogie model with single-axle for straddle-type monorail vehicles

\section{Full-scale dynamic model for the straddle-type mon- orail vehicles with single-axle bogies}

\subsection{Degree of freedom and parameters}

The dynamic model of the straddle-type monorail vehicle includes 3 parts, i.e., 1 vehicle body and 2 bogies. The secondary suspension is adopted for the connection between the vehicle body and the front and rear running parts. In the dynamic model for monorail vehicles, the monorail vehicle body as well as the vertical, horizontal and $\mathrm{X}, \mathrm{Y}$ and $\mathrm{Z}$-axle around of the two bogies are taken into consideration. The degree of freedom of monorail vehicles with single-axle bogies is as shown in Table 1.

Table 1

Degree of freedom of single-axle single-rail trains

\begin{tabular}{|c|c|c|c|c|c|c|}
\hline Vehicle parts and number & Flexible & Transverse & Plunging & Rolling & Nodding & Yawing \\
\hline Vehicle body (1) & $x_{c}$ & $y_{c}$ & $z_{c}$ & $\theta_{c}$ & $\phi_{c}$ & $\varphi_{c}$ \\
\hline Bogie frameworks (2) & $x_{z}$ & $y_{z}$ & $z_{z}$ & $\theta_{z}$ & $\phi_{z}$ & $\varphi_{z}$ \\
\hline Running tires (2) & --- & - & - & - & $\phi_{\beta}$ & - \\
\hline Guide tires (4) & - & - & - & - & - & $\varphi_{r}$ \\
\hline Steady tires (2) & - & - & - & - & - & $\varphi_{r}$ \\
\hline
\end{tabular}

The degree of freedom of each monorail vehicle is 34. The dynamic model of straddle-type monorail vehicles is illustrated in Fig 2. The vehicle parameters are illustrated in the reference [16].

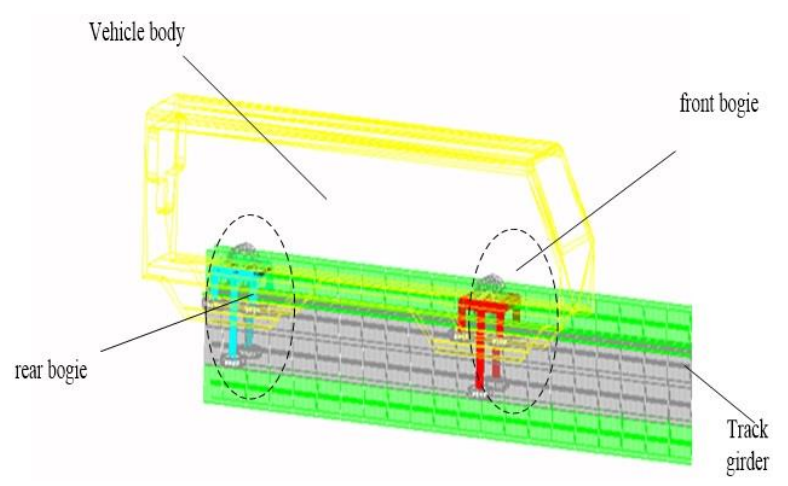

Fig. 2 Full-scale Dynamics model of straddle-type monorail vehicle with single-axis bogies

\subsection{Rail-tire contact model}

The running tire, the guide tire and the steady tire of the straddle-type monorail vehicles are all rubber tires, which have significant nonlinear characteristics due to the complicated elastic structure. During the curve operating process of monorail vehicles, side slipping may be caused during the curve operating process due to the guiding role of the track beam.

Running tire and track beam contact models is described as follows:

$$
\begin{aligned}
& F_{2 i j n}=\frac{1}{4}\left\{m_{h 11} g\left(1-\frac{l_{v x 1}}{l_{v x}}\right)+m_{h 2 i} g\right\}+ \\
& +K 2_{i j n} R 2_{v i j n}+C 2_{i j n} R 2_{i j n} .
\end{aligned}
$$

The models for the contact between the guide wheel, the steady wheel and the track beam are described as follows:

$$
\left\{\begin{array}{l}
F_{3 i j n}=K 3_{i j n} R 3_{i j n}+C 3_{i j n} R 4_{x i j n} \\
F_{4 i j n}=K 4_{i j n} R 4_{i j n}+C 4_{i j n} R 4_{i j n}
\end{array} .\right.
$$

In the equation $K 2_{i j n}, K 3_{i j n} K 4_{i j n}$ are the vertical stiffness of the walking tires, the guide pulley and the steady wheel respectively; $R 2_{i j n}, R 3_{i j n} R 4_{i j n}$ are vertical center of bogies, lateral relative displacements of the guide 
pulley and the steady wheel; $C 2_{i j n}, C 3_{i j n} C 4_{i j n}$ are the vertical damping of the running tire, the radial damping of the guide wheel and the steady wheel; $l_{v x}$ is the distance between the front and rear air springs.
3.3. Motion equations of the straddle-type monorail vehicles with single-axle bogies

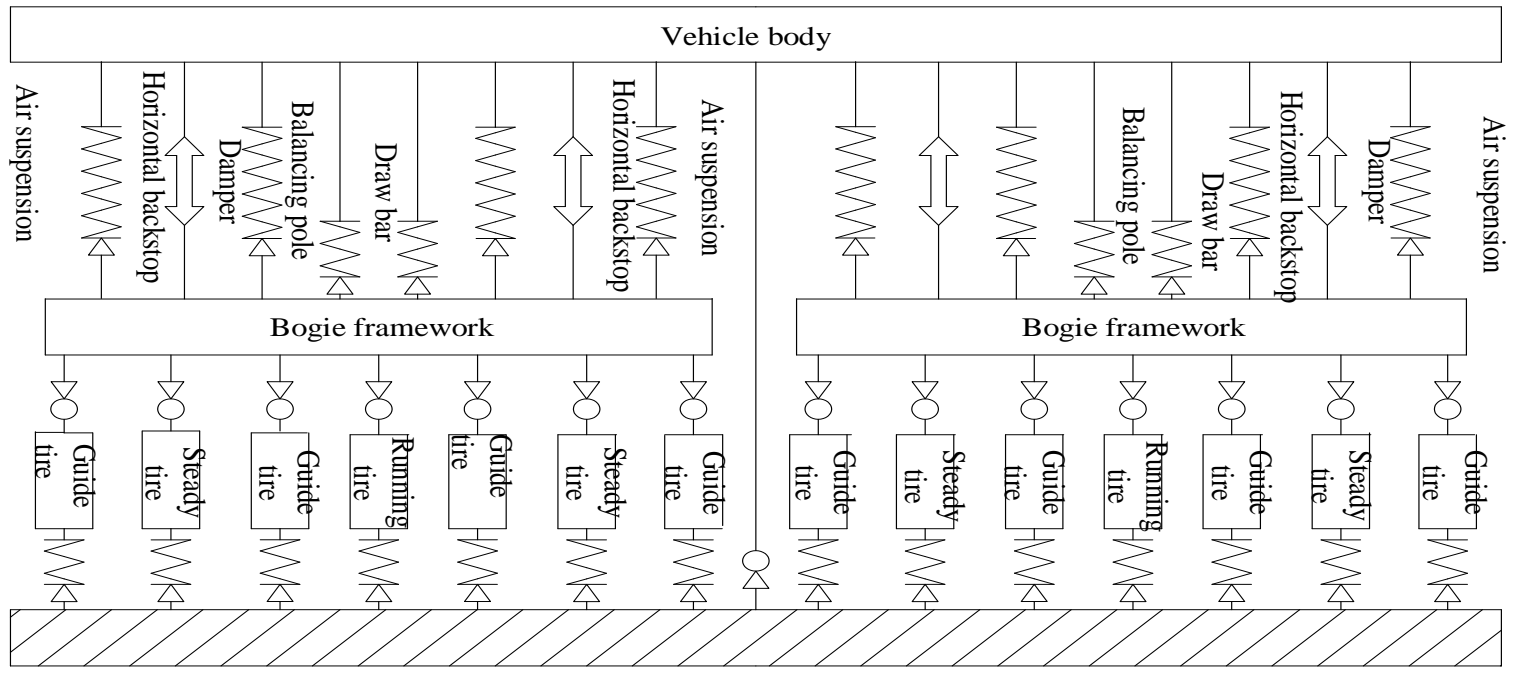

Track beam

Fig. 3 Topology of dynamic model of straddle-type vehicles with single-axle bogies

The motion equations of the body:

$$
\left\{\begin{array}{l}
m_{11}\left(\ddot{z}_{11}-\left(V^{2} \varphi_{s e} / R_{c}\right)\right)=\sum_{i=1}^{2} \sum_{j=1}^{2} \sum_{n=1}^{2}\left[-K 1_{i j n} R 1_{i j n}-C 1_{i j n} \dot{R} 1_{i j n}\right] \\
m_{21}\left(\ddot{y}_{21}-g \varphi_{s e f b}\right)=\sum_{i=1}^{1} \sum_{j=1}^{2} \sum_{n=1}^{2}\left\{\begin{array}{l}
K 5_{i j n} R 5_{i j n}+C 5_{i j n} \dot{R} 5_{i j n}-K 3_{i j n} R 3_{i j n}-C 3 \dot{R} 3_{i j n} \\
-K 4_{i j n} R R_{4 i j n}+C 4_{i j n} \dot{R}_{i j n} \delta_{1 i}
\end{array}\right\} \\
I_{x 11} \ddot{\theta}_{x 11}=\sum_{i=1}^{2} \sum_{j=1}^{1} \sum_{n=1}^{2}\left\{(-1)^{n} L_{y 2}+a\left(K 1_{i j n} R 1_{i j n}+C 1_{i j n} \dot{R} 1_{i j n}\right)-L z_{1}\left(K 5_{i j n} R 5_{i j n}+C 5_{i j n} \dot{R} 5_{i j n}\right) \delta_{1 j}+L z_{1} g \varphi_{s e c}\right\} \\
I_{y 11} \ddot{\theta}_{y 11}=\sum_{i=1}^{2} \sum_{j=1}^{1} \sum_{n=1}^{2}\left\{(-1)^{i} L x_{i}\left(K 1_{i j n} R 1_{i j n}+C 1_{i j n} \dot{R} 1_{i j n}\right)\right\} \\
I_{z 11} \ddot{\theta}_{z 11}=\sum_{i=1}^{2} \sum_{j=1}^{1} \sum_{n=1}^{2}\left\{-(-1)^{i} L x_{i}\left(K 5_{i j n} R 5_{i j n}+C 5_{i j n} \dot{R} 5_{i j n}\right)\right\}
\end{array}\right.
$$

The motion equations of front bogies:

$$
\begin{aligned}
& \left\{\begin{array}{l}
m_{21}\left(\ddot{z}_{2 i}-\left(V^{2} \varphi_{s e_{f b}}\right) / R_{f b}\right)=\sum_{i=1}^{1} \sum_{j=2}^{2} \sum_{n=1}^{2}\left\{\left(K 1_{i j n} R 1_{i j n}+C 1_{i j n} \dot{R} 1_{i j n}\right) \delta_{1 j}-K 2_{i j n} R 2_{i j n}+C 2_{i j n} \dot{R} 2_{i j n}\right\} \\
m_{21}\left(\ddot{y}_{21}-g \varphi_{s e f b}\right)=\sum_{i=1}^{1} \sum_{j=1}^{2} \sum_{n=1}^{2}\left\{\begin{array}{l}
K 5_{i j n} R 5_{i j n}+C 5_{i j n} \dot{R} 5_{i j n}-K 3_{i j n} R 3_{i j n}-C 3 \dot{R} 3_{i j n} \\
-\left(K 4_{i j n} R_{4 i j n}+C 4_{i j n} \dot{R}_{i j n}\right) \delta_{1 j}
\end{array}\right\} \\
I_{x 21} \ddot{\theta}_{x 21}=\sum_{\mathrm{i}=1}^{1} \sum_{j=1}^{1} \sum_{n=1}^{2}\left\{\begin{array}{l}
-(-1)^{n} L y_{2}\left(K 1_{i j n} R 1_{i j n}+C 1_{i j n} \dot{R} 1_{i j n}\right) \delta_{1 j}+(-1)^{n} L y_{4}\left(K 1_{i j n} R 1_{i j n}+C 1_{i j n} \dot{R} 1_{i j n}\right) \\
-L z_{2} g \varphi_{s e \mathrm{fb}}-\left(L \mathrm{z}_{3}+L z_{4}\right)\left(K 3_{i j n} R 3_{i j n}+C 3_{i j n} \dot{R} 3_{i j n}\right)-\left(L z_{3}+L \mathrm{z}_{4}+L \mathrm{z}_{5}\right) \\
\left(K 4_{i j n} R 4_{i j n}+C 4_{i j n} \dot{R} 4_{i j n}\right) \delta_{1 j}
\end{array}\right.
\end{array}\right\} . \\
& \left\{\begin{array}{l}
I_{y 21} \ddot{\theta}_{y 21}=\sum_{i=1}^{1} \sum_{j=1}^{1} \sum_{n=1}^{2}\left\{(-1)^{j} L x_{3}\left(K 2_{i j n} R 2_{i j n}+C 2_{i j n} \dot{R} 2_{i j n}\right)\right\} \\
I_{z 21} \ddot{\theta}_{z 21}=\sum_{i=1}^{1} \sum_{j=1}^{1} \sum_{n=1}^{2}\left\{-(-1)^{j} L x_{4}\left(K 3_{i j n} R 3_{i j n}+C 3_{i j n} \dot{R} 3_{i j n}\right)\right\}
\end{array}\right.
\end{aligned}
$$

The motion equations of rear bogies: 


$$
\left\{\begin{array}{l}
m_{22}\left(\ddot{y}_{21}-g \varphi_{s e r b}\right)=\sum_{i=2}^{2} \sum_{j=1}^{2} \sum_{n=1}^{2}\left\{\begin{array}{l}
K 5_{i j n} R 5_{i j n}+C 5_{i j n} \dot{R} 5_{i j n}-K 3_{i j n} R 3_{i j n}-C 3 \dot{R} 3_{i j n} \\
-\left(K 4_{i j n} R_{4 i j n}+C 4_{i j n} \dot{R}_{i j n}\right) \delta_{1 j}
\end{array}\right\} \\
m_{22}\left(\ddot{z}_{22}-\left(V^{2} \varphi_{s e}\right) / R_{f b}\right)=\sum_{i=2}^{2} \sum_{j=2}^{2} \sum_{n=1}^{2}\left\{\left(K 1_{i j n} R 1_{i j n}+C 1_{i j n} \dot{R} 1_{i j n}\right) \delta_{1 j}-K 2_{i j n} R 2_{i j n}+C 2_{i j n} \dot{R} 2_{i j n}\right\} \\
I_{x 22} \ddot{\theta}_{x 22}=\sum_{i=2}^{2} \sum_{j=1}^{2} \sum_{n=1}^{2}\left\{\begin{array}{l}
-(-1)^{n} L y_{2}\left(K 1_{i j n} R 1_{i j n}+C 1_{i j n} \dot{R} 1_{i j n}\right) \delta_{1 j}+(-1)^{n} L y_{4}\left(K 1_{i j n} R 1_{i j n}+C 1_{i j n} \dot{R} 1_{i j n}\right) \\
-L z_{2} g \varphi_{s e_{r b}}-\left(L z_{3}+L z_{4}\right)\left(K 3_{i j n} R 3_{i j n}+C 3_{i j n} \dot{R} 3_{i j n}\right)-\left(L z_{3}+L z_{4}+L z_{5}\right) \\
\left(K 4_{i j n} R 4_{i j n}+C 4_{i j n} \dot{R} 4_{i j n}\right) \delta_{1 j}
\end{array}\right\} . \\
I_{y 22} \ddot{\theta}_{y 22}=\sum_{i=2}^{2} \sum_{j=1}^{1} \sum_{n=1}^{2}\left\{(-1)^{j} L x_{3}\left(K 2_{i j n} R 2_{i j n}+C 2_{i j n} \dot{R} 2_{i j n}\right)\right\} \\
I_{z 21} \ddot{\theta}_{z 22}=\sum_{i=1}^{2} \sum_{j=1}^{1} \sum_{n=1}^{2}\left\{-(-1)^{j} L x_{4}\left(K 3_{i j n} R 3_{i j n}+C 3_{i j n} \dot{R} 3_{i j n}\right)\right\}
\end{array}\right.
$$

3.4. Unevenness simulation of the rail surface of the track beam

The ISO8608 pavement model is adopted for the rail unevenness model, with the following pavement power spectral density [17]:

$$
G_{d}(\Omega) \frac{\alpha}{\Omega^{n}+\beta^{n}}=G_{d}\left(\Omega_{0}\right)\left(\frac{\Omega_{0}}{\Omega}\right)^{-n} .
$$

In which $\Omega$ is the spatial frequency; $\alpha, \beta$ and $n$ are pavement roughness coefficient, form coefficient and PSD power spectrum index coefficient, respectively.

\section{Characteristics of the vibration response of monorail vehicles}

The ride comfort of vehicles and the passenger experience are directly influenced by the vibration characteristics of single-rail vehicles during running. The vibration response time-course curve acquired based on simulation is adopted to evaluate the stability and comfort of single-axle vehicles. The GB5599-85 and UIC513 [18] is employed for the stability method, with the following calculation methods:

$$
W=7.08 \sqrt{\sum_{i=1}^{n} A_{i}^{3} F\left(f_{i}\right) / f_{i}} .
$$

In which $W$ is the stability index; $A$ is the vibration acceleration; $f$ is the vibration frequency; $F(f)$ is the frequency correction coefficient.

The ISO2631[19] analysis is adopted as the comfort evaluation method, the weighted accelerated speed root-mean-square value on various axles $a_{w j}$ is calculated firstly, and then the total weighted accelerated speed rootmean-square value is calculated as per Formula (8):

$$
a_{w}=\left[\left(a_{x w}\right)^{2}+\left(a_{y w}\right)^{2}+\left(a_{z w}\right)^{2}\right]^{1 / 2} .
$$

4.1. Vibration response of vehicles of different velocities

Based on the dynamic model for single-rail vehicles established above, the influences of velocity and tire stiffness on kinetic vibration of single-rail vehicles are analyzed. The pre-compression of the guide tire and the steady tire is $5000 \mathrm{~N}$. Under the full-load working condition, the vibration acceleration response curves of the vehicle velocities with $V=45 \mathrm{~km} / \mathrm{h}, V=60 \mathrm{~km} / \mathrm{h}$ and $V=75 \mathrm{~km} / \mathrm{h}$ are illustrated in Figs. 4, 5 and 6.

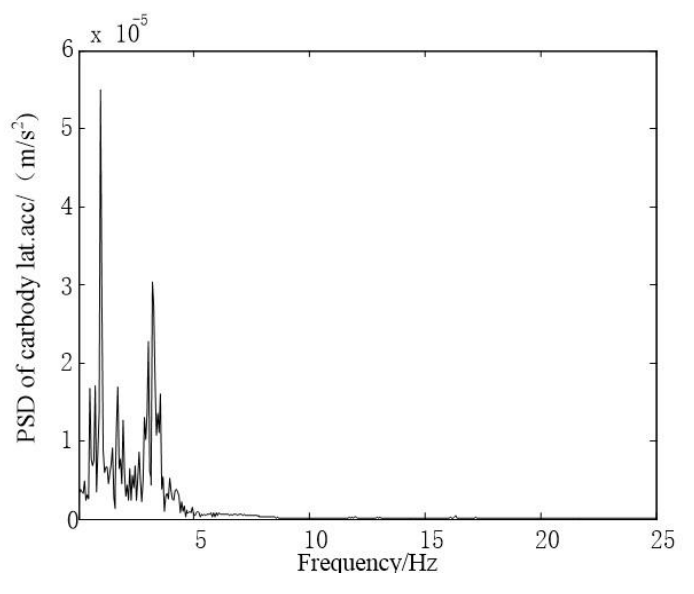

b

Fig. 4 PSD of car body accelerations (a: vertical direction; b: lateral direction, $V=45 \mathrm{~km} / \mathrm{h}$ ) 


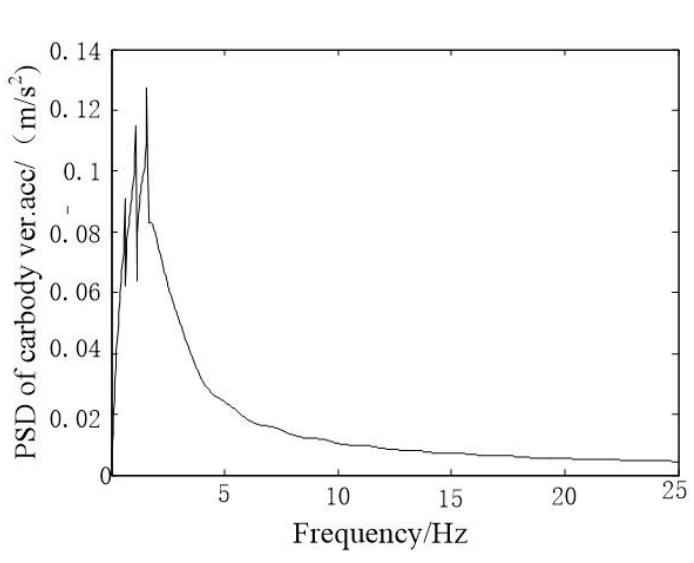

a

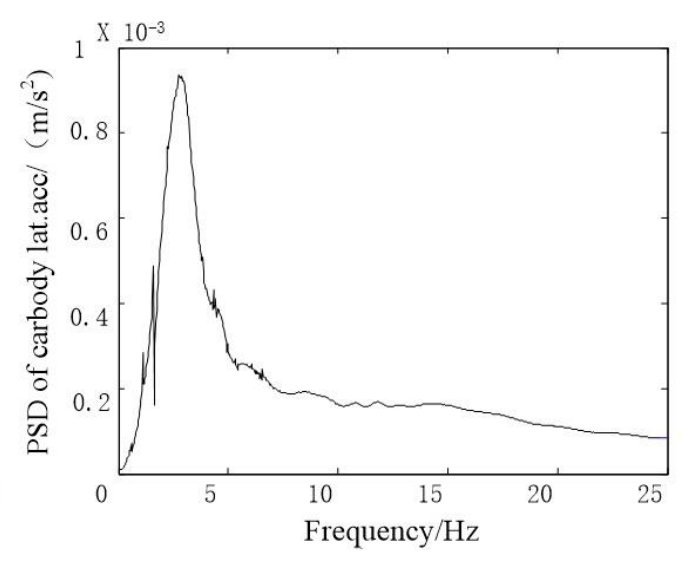

$\mathrm{b}$

Fig. 5 PSD of car body accelerations (a: vertical direction; b: lateral direction=60 km/h)

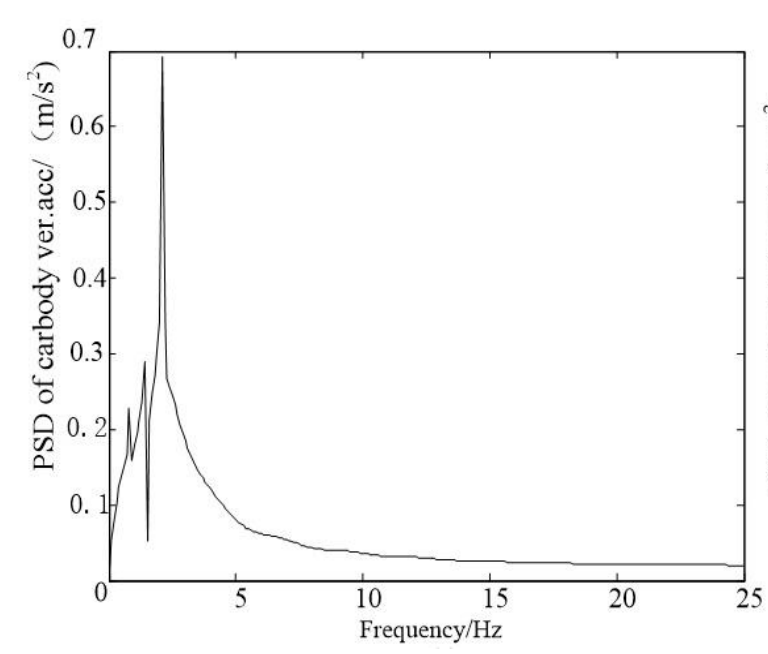

a

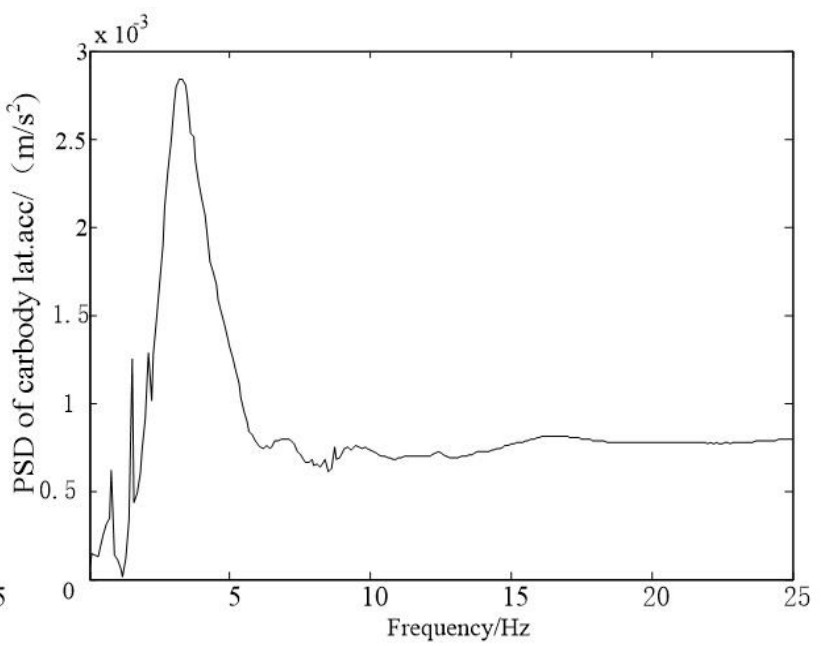

$\mathrm{b}$

Fig. 6 PSD of car body accelerations (a: vertical direction; b: lateral direction, $V=75 \mathrm{~km} / \mathrm{h}$ )

Vibration response of vehicles of different velocities

\begin{tabular}{|c|c|c|c|c|c|c|}
\hline \multirow{2}{*}{$\begin{array}{c}\text { Working } \\
\text { conditions }\end{array}$} & \multirow{2}{*}{$\begin{array}{l}\text { Velocity } \\
(\mathrm{km} / \mathrm{h})\end{array}$} & \multirow{2}{*}{$\begin{array}{c}\text { Vertical acceleration } \\
\left(\mathrm{m} / \mathrm{s}^{2}\right)\end{array}$} & \multirow{2}{*}{$\begin{array}{c}\text { Lateral } \\
\text { acceleration }\left(\mathrm{m} / \mathrm{s}^{2}\right)\end{array}$} & \multicolumn{2}{|c|}{ Stability index } & \multirow{2}{*}{$\begin{array}{l}\text { Riding } \\
\text { comfort }\end{array}$} \\
\hline & & & & Vertical & Lateral & \\
\hline \multirow{3}{*}{ No load } & 45 & 0.1911 & 0.0012 & 1.88155 & 1.67233 & 0.1376 \\
\hline & 60 & 0.4789 & 0.0028 & 2.42253 & 2.274195 & 0.2498 \\
\hline & 75 & 0.9458 & 0.0034 & 2.7908 & 2.7258 & 0.2978 \\
\hline \multirow{3}{*}{ Full load } & 45 & 0.0912 & 0.0001 & 1.85713 & 1.65066 & 0.1517 \\
\hline & 60 & 0.4234 & 0.0013 & 2.20517 & 1.95998 & 0.182 \\
\hline & 75 & 0.8315 & 0.0024 & 2.26138 & 2.20968 & 0.2527 \\
\hline
\end{tabular}

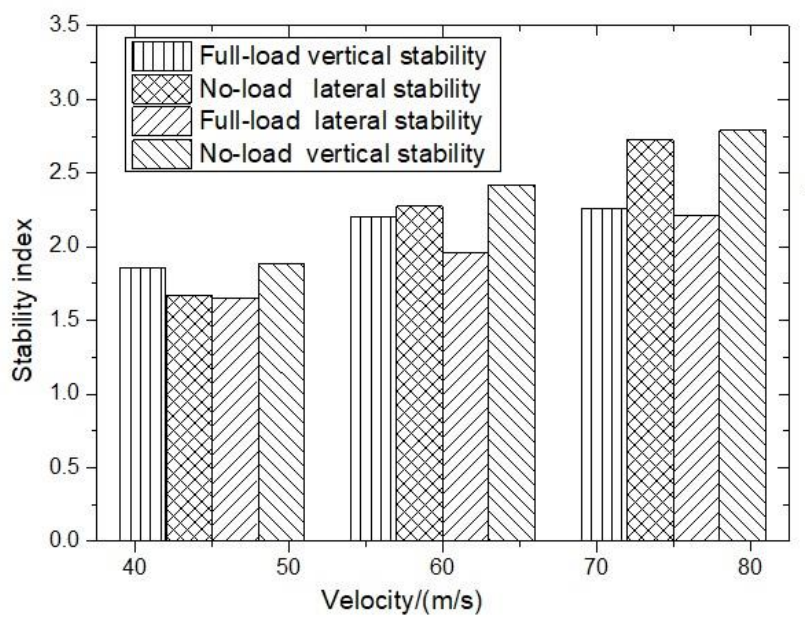

Fig. 7 Stability index with different velocities

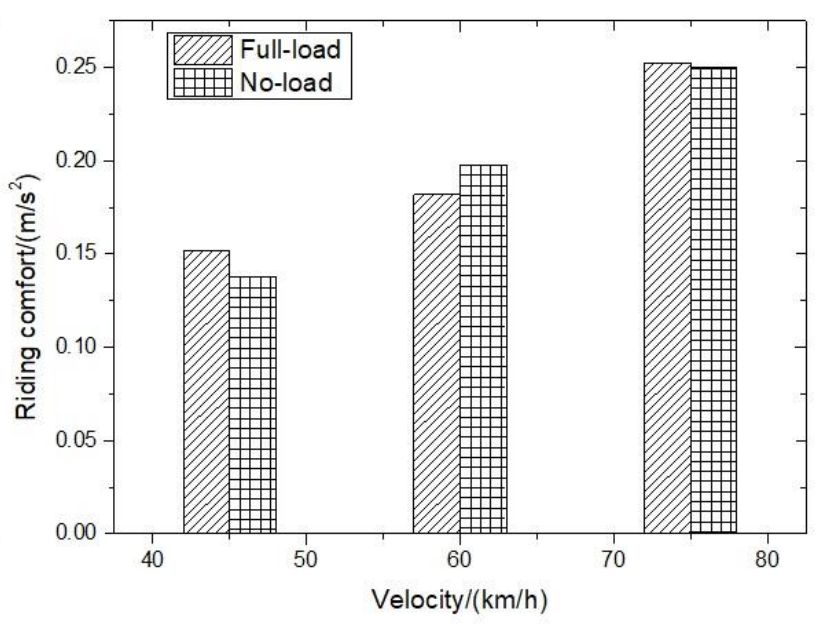

Fig. 8 Riding comfort of different velocities 


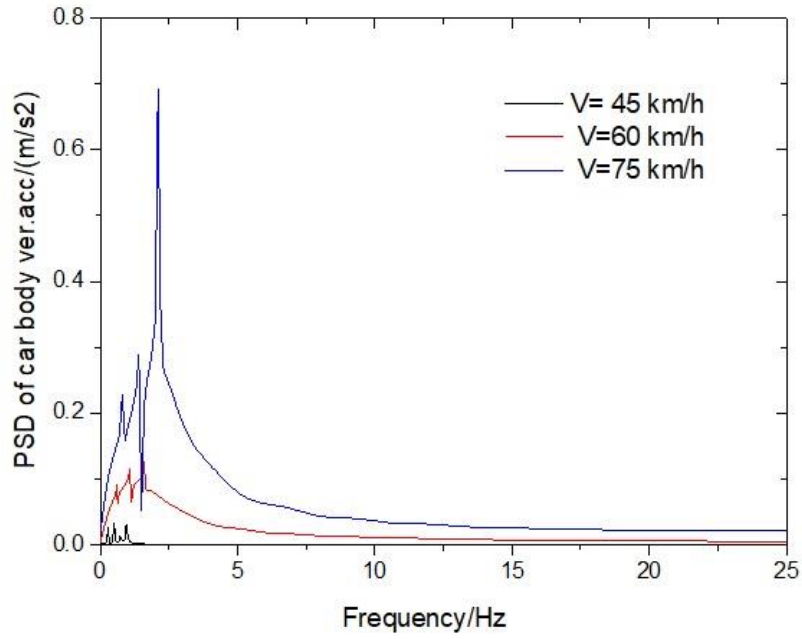

a

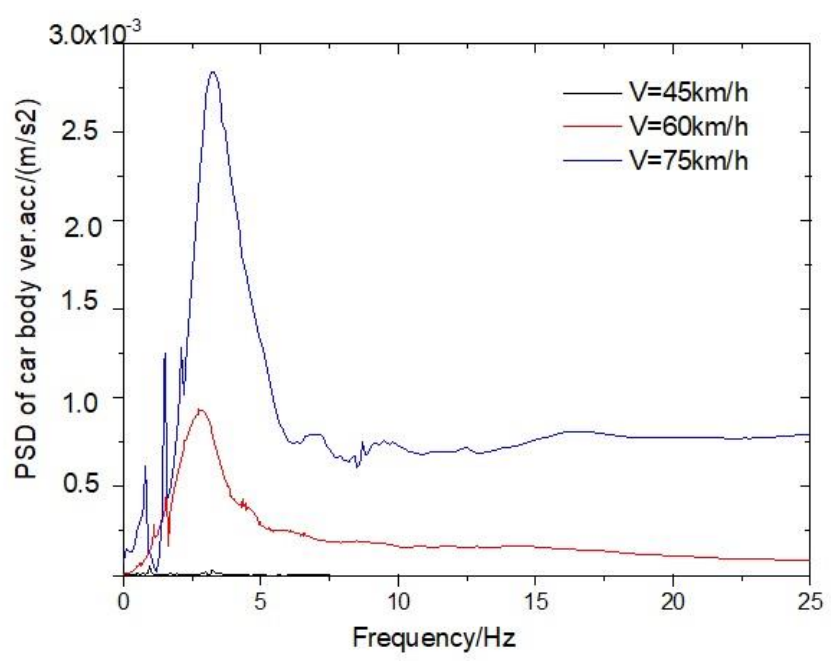

b

Fig. 9 PSD of car body accelerations of different velocities (a: vertical direction; b: lateral direction)

The following conclusions can be drawn according to Fig. 7 and Table 2: 1) the maximum vertical and lateral acceleration of the vehicle is $0.9458 \mathrm{~m} / \mathrm{s}^{2}$ and 0.0034 $\mathrm{m} / \mathrm{s}^{2}$, respectively. 2). the maximum vertical and lateral acceleration are increased with the increase with velocities. $3)$. the riding stability is reduced with the increase of the velocity. 4). the vertical stability is lower than the lateral one with the vehicle with the same velocity and mass. This is because that the vertical vibration has a larger amplitude ratio than that of the lateral vibration (Fig. 9).

According to Fig. 8, the riding comfort is negatively correlated with the velocity. The riding comfort is reduced with the increase with velocity. There is no significant rule on changes between the weight of the vehicle body and the velocity. However, vehicle response is sensitive to changes on velocity.
4.2. Vibration response of different running tire stiffness

The following conclusions can be drawn from Fig. 10 and Table 3: 1) the maximum vertical and lateral acceleration of the vehicle are $0.38038 \mathrm{~m} / \mathrm{s}^{2}$ and 0.00174 $\mathrm{m} / \mathrm{s}^{2}$, respectively. 2). the maximum vertical and lateral acceleration of the vehicle are increased with the growth in stiffness of the running tire. 3 ). the vertical stability and the lateral stability are reduced with the increase in the stiffness of tires. 4). the riding comfort is reduced with the increase in stiffness of the running tire. Based on Figure 10, with the changes of stiffness, no change is made on phase frequency, but certain change is made on the amplitude. The frequency response is reduced with the increase in stiffness, leading to better stability and riding comfort.

Vibration response of vehicles of different stiffness of running tires ( $V=60 \mathrm{~km} / \mathrm{h})$

Table 3

\begin{tabular}{|c|c|c|c|c|c|c|}
\hline \multirow{2}{*}{$\begin{array}{c}\text { Working } \\
\text { conditions }\end{array}$} & $\begin{array}{c}\text { Tire stiffness } \\
(\mathrm{N} / \mathrm{m})\end{array}$ & $\begin{array}{c}\text { Vertical accelera- } \\
\text { tions }\left(\mathrm{m} / \mathrm{s}^{2}\right)\end{array}$ & \multirow{2}{*}{$\begin{array}{c}\text { Lateral } \\
\text { acceleration }\left(\mathrm{m} / \mathrm{s}^{2}\right)\end{array}$} & \multicolumn{2}{|c|}{ Stability } & Riding comfort \\
\cline { 5 - 7 } & $1.0 \times 10^{6}$ & 0.24193 & 0.00163 & 2.5230 & 0.9177 & \\
\cline { 2 - 7 } No-load & $2.0 \times 10^{5}$ & 0.38038 & 0.00174 & 2.2049 & 0.8562 & 0.1344 \\
\cline { 2 - 7 } & $4.0 \times 10^{6}$ & 0.34546 & 0.00173 & 2.0487 & 0.8389 & 0.1289 \\
\hline \multirow{3}{*}{ Full-load } & $1.0 \times 10^{6}$ & 0.22712 & 0.00101 & 2.5230 & 0.8979 & 0.1255 \\
\cline { 2 - 7 } & $2.0 \times 10^{6}$ & 0.27038 & 0.00114 & 2.2049 & 0.8352 & 0.1145 \\
\cline { 2 - 7 } & $4.0 \times 10^{6}$ & 0.23547 & 0.00112 & 2.0487 & 0.7921 & 0.1078 \\
\hline
\end{tabular}

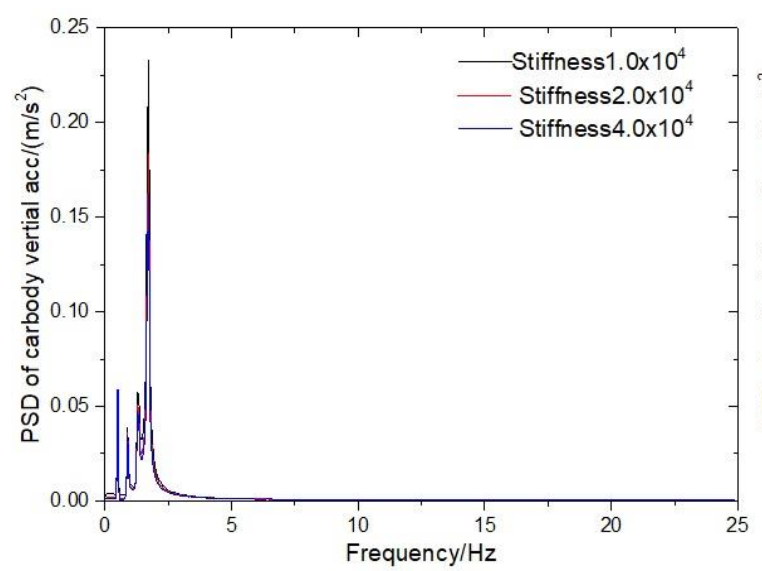

a

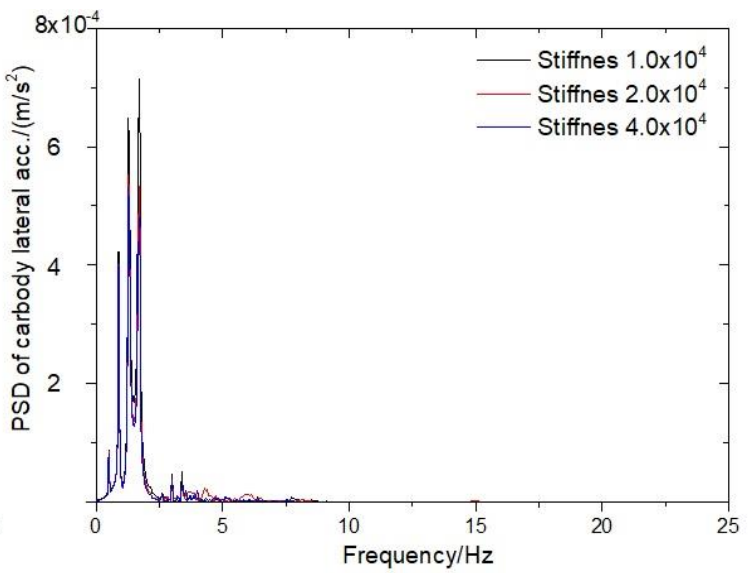

b

Fig. 10 PSD of car body accelerations of different running tires (a: vertical direction; b: lateral direction) 


\section{Conclusions}

Aiming at the vibration response characteristics of straddle-type rail traffic vehicles with single-axle bogie on random rail surface, the topological relation of the straddle-type monorail vehicles with single-axle bogies is analyzed in this article. The full-scale dynamic model of the straddle-type monorail vehicles with single-axle bogies with degree of freedom of 34 is established, including the tire-track beam contact model, with the following main conclusions: with velocity.

1) The riding comfort is reduced with the increase

2) The vertical stability is lower than the lateral one of the vehicle of the same mass. It is caused because that the vertical vibration amplitude ratio is larger than the vibration (Fig. 7).

3) No change is made on frequency phase with the changes on stiffness. But certain change is made on amplitude. The frequency response is reduced with the increase in stiffness, leading to better stability and riding comfort (Table 3 and Fig. 10).

\section{Acknowledgments}

This work was supported by the National Natural Science Foundation of China (Grant No. 51475062) and by the Artificial Intelligence Key Laboratory of Sichuan Province (Grant No. 2017RYY04) and Project of Sichuan Provincial Department of Education (Grant No. 18ZB0423).

\section{References}

1. Timan, P. E. 2015. Why monorail systems provide a great solution for metropolitan areas, Urban Rail Transit 1(1):13-25. http://dx.doi.org/10.1007/s40864-015-0001-1.

2. Suda, Y.; Shibano, K.; Matsumoto, A.; Sato, Y.; Ohno, H.; Nishimura, S.-I.; Oka, Y.; Suzuki, M. 2002. Dynamic characteristics of a single-axle truck for compatibility between stability and curving performance, Vehicle System Dynamics, 37(sup1):616629.

http://dx.doi.org/10.1080/00423114.2002.11666267.

3. Diana, G.; Cheli, F.; Collina, A.; Corradi, R.; Melzi, S. 2002.The development of a numerical model for railway vehicles comfort assessment through comparison with experimental measurements, Vehicle System Dynamics 38(3):165-183. http://dx.doi.org/10.1076/vesd.38.3.165.8287.

4. Kim, Y. K. H. W. S. K. C. K. T. 2003.Correlation of ride comfort evaluation methods for railway vehicles, Proceedings of the Institution of Mechanical Engineers Part F -Journal of Rail \& Rapid Transit, 217(2):73-88. https://dx.doi.org/10.1243/095440903765762823.

5. Cheng, Y. C.; Hsu, C. T. 2014. Running safety and comfort analysis of railway vehicles moving on curved tracks, International Journal of Structural Stability and Dynamics 14(04):1450004. http://dx.doi.org/10.1142/s0219455414500047.

6. Yoo, B. S. K. a. H. H. 2013. Ride comfort uncertainty analysis and reliability design of a passenger vehicle undergoing random road excitation, Proceedings of the Institution of Mechanical Engineers Part D Journal of
Automobile Engineering 227(3):433-442. http://dx.doi.org/10.1177/0954407012458754.

7. Kumar, V.; Rastogi, V.; Pathak, P. M. 2016. Simulation for whole-body vibration to assess ride comfort of a low-medium speed railway vehicle, Simulation 93(3):225-236. http://dx.doi.org/10.1177/0037549716679254.

8. Lee, C. M.; Goverdovskiy, V. N.; Sim, C. S.; Lee, J. H. 2016. Ride comfort of a high-speed train through the structural upgrade of a bogie suspension, Journal of Sound and Vibration 36(1):99-107. http://dx.doi.org/10.1016/j.jsv.2015.07.019.

9. Sharma, S. K.; Kumar, A. 2017. Impact of electric locomotive traction of the passenger vehicle Ride quality in longitudinal train dynamics in the context of Indian railways, Mechanics \& Industry 18(2):222. http://dx.doi.org/10.1051/meca/2016047.

10. Kutluay, E.; Winner, H. 2014.Validation of vehicle dynamics simulation models - a review, Vehicle System Dynamics 52(2):186-200. http://dx.doi.org/10.1080/00423114.2013.868500.

11. Cao, Y.; Xia, H.; Lu, W.; Wang, K.; Calçada, R. 2014. A numerical method to predict the riding comfort induced by foundation construction close to a highspeed-line bridge, Proceedings of the Institution of Mechanical Engineers, Part F: Journal of Rail and Rapid Transit, 229(5):553-564.

http://dx.doi.org/10.1177/0954409713519087.

12. Naeimi, M.; Tatari, M.; Esmaeilzadeh, A.; Mehrali, M. 2015. Dynamic interaction of the monorail-bridge system using a combined finite element multibodybased model, Proceedings of the Institution of Mechanical Engineers, Part K: Journal of Multi-body Dynamics 229(2):132-151. http://dx.doi.org/10.1177/1464419314551189.

13. Wang, H.; Zhu, E.; Chen, Z. 2017. Dynamic response analysis of the straddle-type monorail bridge-vehicle coupling system, Urban Rail Transit 3(3):172-181. http://dx.doi.org/10.1007/s40864-017-0069-x.

14. Wen Xiao xia, D. Z., Xu Zhouzhou, Yi Yanli, Wei Hanbing. 2017. The coupling dynamic model and vibration response of straddle type monorail vehicle, Journal of Vibration Measurement \& Diagnosis 37(3):462-468.

http://dx.doi.org/10.16450/j.cnki.issn.10046801.2017.0 3.007.

15. MacIel, G. P. R.; Barbosa, R. S. 2016. Monorail vehicle model to study influence of tyre modelling on overall dynamics, International journal of heavy vehicle systems 23(4):317-332. http://dx.doi.org/10.1504/IJHVS.2016.079270.

16. Janjic, D. 2013. Dynamic train-bridge interaction in Monorail Sao Paulo Metro Line 2, 36th International Association for Bridge and Structural Engineering Symposium on Long Span Bridges and Roofs Development, Design and Implementation, International Association for Bridge and Structural Engineering (IABSE), Kolkata, India.

17. Bao, Y.; Li, Y.; Ding, J. 2016. A case study of dynamic response analysis and safety assessment for a suspended monorail system, International Journal of Environmental Research and Public Health 13(11):1-11. http://dx.doi.org/10.3390/ijerph13111121.

18. Guidenlines for Evaluating Passenger Comfort in 
Relation to Vibration in Railway Vehicles. 1994. International Union of Railways.

19. Mechanical Vibration and Shock - Evaluation of Human Exposure to Whole-Body Vibration in: Part 1: General requirement. 1997. International Organization for Standardization ISO 2631-1

Junchao Zhou, Zixue Du, Zhen Yang

\section{DYNAMIC RESPONSE OF THE FULL-SCALE STRADDLE-TYPE MONORAIL VEHICLES WITH SINGLE-AXLE BOGIES}

S u m m a r y

The research on vibration response on random pavement is conducted to evaluate the riding stability and comfort of a new straddle-type monorail vehicle with single-axle bogies. The topology of straddle-type monorail vehicles with single-axle bogie is analyzed, and the fullscale dynamic model of single-axle bogie straddle-type rail transit vehicles of 34 degree of freedom and the tire-track beam contact model are established. Based on the dynamic model, the random vibration influence characteristics of vehicles of different velocities and tire stiffness are analyzed. Based on the research the riding stability and comfort are reduced with the increase in velocities and tire stiffness. The vertical stability is lower than the horizontal one with the vehicle with the same velocity and mass. This is because that the vertical vibration has a larger amplitude ratio than that of the horizontal vibration. No change is caused on frequency phase with the changes on stiffness. But certain change is made on amplitude. The frequency response is reduced with the increase in stiffness, leading to better stability and riding comfort.

Keywords: straddle-type monorail vehicles, vibration response, single-axle bogies, full-scale dynamic model.

Received October 27, 2018

Accepted February 15, 2019 